\title{
A Case of Neospora Associated Bovine Abortion in Sweden
}

Neospora caninum is a recently recognized protozoan organism that causes fatal neuromuscular disease in dogs and abortions and stillbirths in cattle and other animals (Dubey \& Lindsay 1993). The parasite is morphologically similar and phylogenetically very closely related to the cyst-forming coccidium Toxoplasma gondii (Ellis et al. 1994, Holmdahl et al. 1994). This group of parasites has a twohost life cycle principally involving a carnivorous definitive host and a herbivorous or omnivorous intermediate host. However, with $N$. caninum, there is as yet no knowledge of any definitive host harbouring sexual stages of the parasite. The only known route of transmission is vertical from mother to foetus ( $\mathrm{Du}$ bey \& Lindsay 1993).

Abortions constitute a regular problem in dairy cattle worldwide, causing considerable economic setbacks. Among infectious causes, viral, bacterial, fungal, as well as protozoan agents, are recognized. Although $T$. gondii is well known as a major cause of ovine and caprine abortion, this parasite has not been incriminated for abortion in cattle. However, since the first report of Neospora-like organisms as the cause of bovine abortion (Thilsted \& Dubey 1989) this agent has been reported from all continents as responsible for single cases, as well as outbreaks, of abortions in cattle (Dubey \& Lindsay 1993). N. caninum has been demonstrated as a cause of neurological disorder in dogs in Sweden (Uggla et al. 1989), but the parasite has not been described from other host species in this country. A dairy farm in the vicinity of Uppsala, Sweden, free of bovine virus diarrhoea virus (BVDV) infection, had experienced excessive numbers of abortions with unknown etiology. As part of an investigation all adult animals ( $\mathrm{n}=35$ ) on the farm were bloodsampled for antibodies against $N$. canınum and $T$. gondii. The serum analyses for $N$. caninum were carried out with an indirect fluorescent antibody test (IFAT) and an enzyme linked immunosorbent assay (ELISA), employing an iscom (immunostimulating complex) antigen as modified from Björkman et al. (1994). Tachyzoites of the canine isolate, $N$. canininum NC-1 (Dubey et al. 1988) were used as antigen in the IFAT analyses and for the production of iscoms. The analyses for $T$. gondii were carried out with a direct agglutination test (Toxoscreen DA; bioMérieux, Marcy-l'Etoile, France). During the course of the investigation on the farm, a foetus, which had been aborted at 4.5 months of gestation, was referred to the laboratory for post mortem analysis. The foetus was necropsied and specimens of the brain, spinal cord, heart, liver, lung and spleen were fixed in $10 \%$ neutral buffered formalin for histological examination. Sections were stained with haematoxylin and eosin and with a peroxidase anti-peroxidase immunohistochemical technique (PAP) employing a rabbit anti $N$. caninum serum 


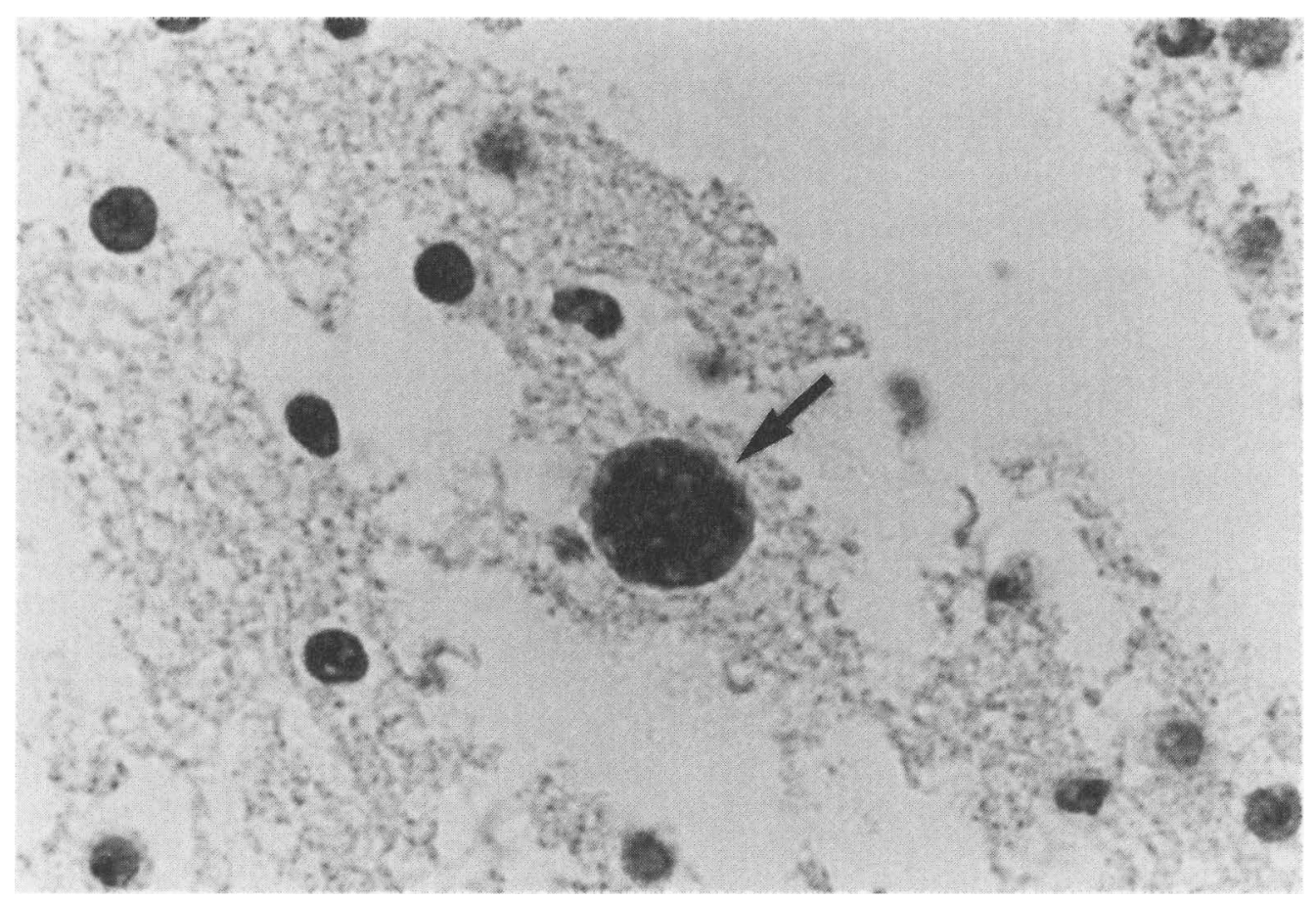

Figure 1. Cerebrum of aborted bovine foetus. A group of Neospora organisms stained with ant1 N. caninum antibodies (arrow). PAP x 1300.

(Lindsay \& Dubey 1989). Sections of the brain were also stained with a $T$. gondii PAP (Uggla et al. 1987).

The serological investigation revealed that 10 of the 35 animals tested had antibodies to $N$. caninum, but none had antibodies to $T$. gondii. At necropsy of the foetus no gross lesions were seen. Histologically, no obvious changes were detected in the fetal tissues investigated. Especially the sections of the central nervous system were difficult to judge due to autolytic changes. In the cerebrum, however, the immunohistochemical staining revealed a few groups of protozoan organisms that stained specifically with the anti $N$. caninum serum (Fig. 1.), but not with the anti $T$. gondii serum. No protozoan organisms were detected else- where. Significant levels of antibodies to $N$. caninum were detected in sera from both the mother and the grandmother of the foetus.

The immunohistochemical findings tallies with previous descriptions of Neospora associated abortions in cattle (Dubey \& Lindsay 1993), and the serological results further support the diagnosis. Since the present case represents the first documentation of Neospora associated bovine abortion in Sweden, it is essential that further clinical as well as laboratory attention is paid to this problem, also in Scandinavia.

\section{Acknowledgements}

This study was supported by the Ivar and Elsa Sandberg Foundation and the Swedish Council for Fo- 
restry and Agricultural Research. The assistance and advice of Katarına Gustafsson, Jens G Mattsson, Per Olle Nilsson, Jan Persson and Susanne Stenlund are gratefully acknowledged. The study was part of the EU research collaboration COST 820.

\section{O J M. Holmdahl, ${ }^{1,2}$ C. Bjorkman ${ }^{2}$ and A. Uggla ${ }^{1}$} ${ }^{1}$ Department of Parasitology, Swedish University of Agricultural Sciences and National Veterinary Inst1tute, P.O. Box 7073, S-750 07, Uppsala, Sweden.

${ }^{2}$ Department of Cattle and Sheep Diseases, Swedish University of Agricultural Sciences, P.O. Box 7019, S-750 07 Uppsala, Sweden.

\section{References}

Bjorkman C, Lundén A, Holmdahl J, Barber J, Trees AJ, Uggla A: Neospora caninum in dogs: Detection of antıbodies by ELISA using an 1scom ant1gen. Parasite Immunol. 1994, 16, 643-648.

Dubey JP, Hattel AL, Lindsay DS, Topper MJ: Neonatal Neospora canınum infection in dogs: Isolation of the causative agent and experimental transmission. J. Amer. vet. med. Assoc. 1988, $193,1259-1263$.
Dubey JP, Lindsay DS $\cdot$ Neosporosis. Parasitol. Today $1993,9,452-458$.

Ellis J, Luton $K$, Baverstock PR, Brindley PJ, Nimmo KA, Johnson AM. The phylogeny of Neospora canınum. Mol. biochem. Parasitol. 1994, 64, 303-311.

Holmdahl OJM, Mattsson JG, Uggla A, Johansson $K-E$ : The phylogeny of Neospora canınum and Toxoplasma gond $\iota$ based on ribosomal RNA sequences. FEMS Microbiol. Lett. 1994, 119, 187 192.

Lindsay DS, Dubey JP: Immunohistochemical diagnosis of Neospora caninum in tissue sections. Amer. J. vet. Res. 1989, 50, 1981-1983.

Thilsted JP, Dubey JP: Neosporosis-like abortion in a herd of dairy cattle. J. vet. diagn. Invest. 1989, 1, 205-209.

Uggla A, Dubey JP, Lundmark G, Olson P: Encephalomyelitis and myositis in a boxer puppy due to a Neospora-like infection. Vet. Parasitol. 1989, 32, 255-260.

Uggla A, Sjoland L, Dubey JP. Immunohistochemical diagnosis of toxoplasmosis in fetuses and fetal membranes of sheep. Amer. J. vet. Res. 1987, $48,348-351$.

(Recelved January 20, 1995, accepted March 15, 1995)

Reprints may be obtained from: O J.M. Holmdahl, Department of Parasitology, Swedish University of Agrucultural Sciences, P.O. Box 7073, S-750 07 Uppsala, Sweden. 


